\section{Design and In Vitro Evaluation of Chrono Modulated Theophylline Tablets \\ Vijaya Kumar ${ }^{*}{ }^{*}$, Nagaraj $B^{2}$, Agaiah $B^{3}$, Rambhau $D^{2}$ Jangaon Institute of Pharmaceutical Sciences Jangaon, Warangal, (A.P), India ${ }^{1}$ \\ University College of Pharmaceutical sciences Kakatiya University, Warangal, (A.P), India ${ }^{2}$ \\ S.R.R. College of Pharmaceutical sciences. Valbhapur, Karimnagar} (A.P). India ${ }^{3}$

\author{
Corresponding Author \\ DR.B.Vijaya Kumar \\ 91-0870-2438844 \\ E-mail: banalanagaraj@yahoo.com
}

Received-17 November 2008 Accepted for Publication-5 December, 2008

\begin{abstract}
The objective of this research work was to prepare a chrono modulated delivery system to meet chronopharmacological needs of asthma. In this study theophylline was selected as a model drug. To meet this objective we considered an initial lag phase of release for 3-5 hrs and later a rapid (surge) release phase. To achieve surge release a rapidly releasing core tablet of theophylline was developed by admixing theophylline with effervescent granules and super disintegrants. The lag phase in release was achieved by coating the EV core tablets with release retarding polymer EUDRAGIT RS-100 containing HPMC, further over coated with enteric polymer CAP. The results indicate that a rapidly releasing EV tablet of theophylline cab be developed which when coated with the polymers a lag phase of 2 hrs was achievable followed by a surge release.
\end{abstract}

Key Words: Theophylline, Chrono Modulated Drug Delivery, Asthma.

\title{
INTRODUCTION
}

The role of circadian rhythms in the pathogenesis and treatment of asthma indicates that airway resistance increases progressively at night in asthmatic patients (Martin et al., 1998). Because bronco constriction and exacerbation of symptoms vary on circadian fashion, asthma is well suited for chronotherapy. Chronotherapy of asthma has been extensively studied (Arkinstall, 1988; Goldenheim et al., 1987). The symptoms of asthma worsen during midnight and early morning hours for such diseases, an initial lag phase of release for 3-5 hrs and later a rapid release have to be considered. With the documentation of nocturnal asthma, investigations have focused on effective therapies to treat nocturnal asthma. Previous studies have used various agents such as sustained released aminophylline (Barnes et al., 1982), slow-release salbutamol (Fairfax et al., 1980), and slow-release terbutaline (Postma et al., 1986). The major objective of chronopharmaceutics is to deliver the drug in higher concentrations during the time of greatest need and in lesser concentrations when the need is less to minimize unnecessary side effects. Examples of ChrDDS on the market include compounds such as theophylline (Uniphyl), famotidine (Pepcid), simvastatin (Zocor), COER-Verapamil (Covera-HS, Verelan PM), diltiazem (Cardizem LA) and propranolol (Inna Pran XL). Several chronopharmaceutical technologies are adopted to deal with chronotherapy issues. The key technologies include CONTIN ${ }^{\circledR}$, OROS $^{\circledR}, \operatorname{CODAS}^{\circledR}$, CEFORM ${ }^{\circledR}$, DIFFUCAPS ${ }^{\circledR}$ AND TIMERx, etc (BI-Botti et al., 2004). We in this investigation aim at developing an oral delivery system with an initial lag phase (LP) by coating the tablet with release retarding polymers, followed by 'surge' release phase (SR). We propose to achieve 'surge' release by $\mathrm{CO}_{2}$ gas pressure generated by effervescence composition, which normally contains an organic acid and bicarbonate. We intend to achieve 'surge' release tablets by effervescence triggered gas pressure and lag phase in release by coating the tablet with release retarding polymers.

\section{EXPERIMENTAL}

\section{Materials}

Theophylline and sodium starch glycolate were gift sample from Dynamed Pharmaceuticals P.Ltd., Hyderabad. Eudragit RS-100 was a gift sample from Microlabs, Bangalore, Cellulose acetate phthalate(CAP) and Hydroxypropyl methyl cellulose $30 \mathrm{Cps}$ (HPMC) were gift samples from 
Dr. Reddy's Laboratories, Hyderabad. Polyvinyl pyrrolidone K30 (PVP) was a gift sample from Acto Pharmaceuticals, Wgl. all other chemicals were reagent grade.

\section{Preparation of Theophylline Effervescent Tablets}

Rapidly releasing theophylline effervescent tablets were prepared by using the formula shown in Table 1. Each tablet of average weight $300 \mathrm{mg}$ contains $100 \mathrm{mg}$ of theophylline.

Tablets were prepared by conventional non-aqueous wet granulation method using $5 \%$ PVP as binder in isoproponol. The tablet granulations were compressed into tablets to a hardness of $4-$ $5.5 \mathrm{~kg} / \mathrm{cm}^{2}$ on a 16 station tablet machine

Table: 1 Formula of theophylline effervescent tablets

\begin{tabular}{|l|l|}
\hline Theophylline & $340 \mathrm{G}$ \\
Sodium bicarbonate & $212 \mathrm{G}$ \\
Tartaric acid & $112 \mathrm{G}$ \\
Citric acid & $76 \mathrm{G}$ \\
Sodium starch glycolate & $50 \mathrm{G}$ \\
Lactose & $190 \mathrm{G}$ \\
Talc & $10 \mathrm{G}$ \\
Magnesium stearate & $10 \mathrm{G}$ \\
\hline
\end{tabular}

\section{Estimation of Theophylline}

An U.V. spectrophotometric method based on the measurement of absorption at $272 \mathrm{~nm}$ in a phosphate buffer of $\mathrm{pH} 7.4$ was used for the estimation of theophylline. The method was validated for linearity, accuracy, precision and interference.

\section{Evaluation of uncoated tablets}

Hardness of the tablets was tested using a Monsanto hardness tester. Friability of the tablets was determined in a Roche friabilator. Theophylline content of the tablets was estimated by the spectrophotometric (Elico SL 159) method as described above. Disintegration time of the tablets was determined using a Thermonic tablet disintegration test machine using distilled water as fluid. Results are shown in Table 2.

\section{Coating of effervescent tablets}

Eudragit RS-100 (2, 4, 6, $8 \% \mathrm{w} / \mathrm{v})$ containing 10\% PEG-400 as plasticizer was dissolved in dichloromethane. Similarly solutions containing RS-100 (6\%) and HPMC in the proportions of 5, 7.5 and $10 \%$ of weight of polymer were prepared using dichloromethane and isopropanol (3:1) mixture. The coating solution of cellulose acetate phthalate $(5 \% \mathrm{w} / \mathrm{w})$ containing $10 \%$ castor oil as plasticizer was prepared by dissolving in acetone.

Tablets in lots of $300 \mathrm{gm}$ were either coated with plain Eudragit RS-100 or RS-100 containing varying amounts of HPMC till the tablets has gained weights upto 2, 4, 6 or $8 \%$ due to film deposit. Finally tablets coated with plain Eudragit or Eudragit + HPMC were further coated with CAP solution till they gained $5 \%$ weight due to film deposit. Various lots of tablets such as Eudragit, Eudragit + HPMC or Eudragit + HPMC over coated with CAP were cured by drying them at $50^{\circ} \mathrm{C}$ for overnight. In case of all coatings, always a tablet charge of $300 \mathrm{gm}$ was used. Coating solution was sprayed at a rate of $2 \mathrm{ml} / \mathrm{min}$ and spray cycle was monitored with spraying for 10 seconds and non-spraying phase of 5 seconds, while coating pan was rotated at a speed of $25 \mathrm{rpm}$ and during entire coating period warm air $\left(40^{\circ} \mathrm{C} \pm 3\right)$ was continuously supplied.

\section{Dissolution testing of tablets}

Profiles of the tablets were obtained using USP dissolution test apparatus (Lab India 8 station) with a paddle stirrer. Tablet was placed in the dissolution vessel and stirrer was rotated at $100 \mathrm{rpm}$. The dissolution of the tablets which are not enteric coated was carried out in $7.4 \mathrm{pH}$ phosphate buffer medium. However for the enteric coated tablets dissolution for the first 3 hours was carried out using $1.12 \mathrm{pH}$ buffer followed by phosphate buffer of 7.4. Samples $(5 \mathrm{ml})$ were withdrawn at preset time intervals, filtered via $0.2 \mu$ membrane and filtered samples were analyzed for theophylline 
using UV-spectrophotometer at $272 \mathrm{~nm}$. The sample of dissolution fluid withdrawn at each time was replaced with fresh fluid. The dissolution experiments were conducted in triplicates.

\section{RESULTS AND DISCUSSION}

A rapidly releasing core tablet of theophylline was developed by admixing theophylline with effervescent granules and super disintegrants. The average values of theophylline content, hardness, friability and disintegration time were given in Table 2. The pattern of release of theophylline from such a tablet is shown in Fig. 1 About $75 \%$ of theophylline is released in 15 minutes and $100 \%$ in 45 minutes.

Table 2 Characteristics of uncoated effervescent theophylline tablets

\begin{tabular}{ccccc}
\hline $\begin{array}{c}\text { Assay of } \\
\text { tablets (\%) }\end{array}$ & Friability & D.T. in minutes & Weight in Variation & $\begin{array}{c}\text { Hardness } \\
\left(\mathbf{K g} / \mathbf{c m}^{2}\right)\end{array}$ \\
\hline 99.2 & 0.19 & $2.5 \pm 0.6$ & 0.18 & 4.5 \\
\hline
\end{tabular}

These effervescent tablets of theophylline were coated with Eudragit RS 100. Such a coating retarded the release gradually with increase in the concentration RS-100 (Fig.2). Our earlier experimentation revealed superior impervious film forming tendency of RS-100 over RL- 100 .

Hence RS-100 was chosen in these experiments. The applied films were highly impervious, and have not allowed $100 \%$ release even after 24 hours. To improvise the permeability characteristics of RS-100 films, we have incorporated HPMC in films to create hydration channels in the films. With increase in HPMC concentration in the film release improved dramatically and over $60-80 \%$ release was achieved within 4hours (Fig. 3).

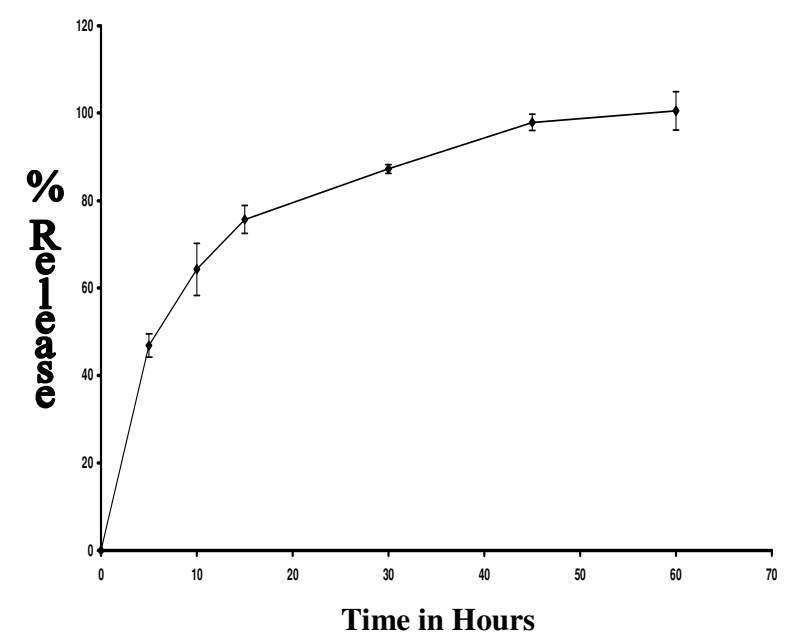

Fig 1: Release profile of effervescent theophylline tablet.

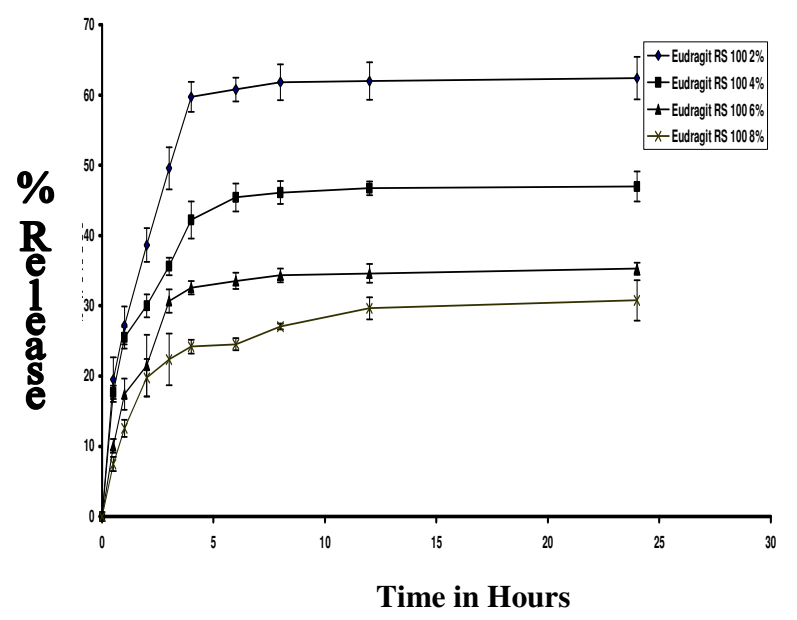

Fig 2: Release profiles of theophylline effervescent tablets on coating with various concentrations of Eudragit RS 100.

In accordance with chronotherapeutic model for nocturnal asthma, an initial lag phase of 3-4 hours is necessary where drug release should be minimal or absent. To achieve this, EV core tablets of theophylline were coated with films of Eudragit RS 100 with HPMC and were further coated with an enteric polymer (cellulose acetate phthalate). This coat has enabled us to achieve definite nonrelease lag phase for 2 hours. But irrespective of HPMC concentration, lag phase remained constant at 2 hours. However the post lag phase release rate of theophylline significantly differed with HPMC concentration in the films. The post lag phase release rate increased with increase in HPMC concentration. At $10 \%$ HPMC, about $80 \%$ of theophylline was released after lag phase, within $1 \frac{1}{2}$ h. At $1 \mathrm{~h}$ it was $60 \%$ (Fig.4). 


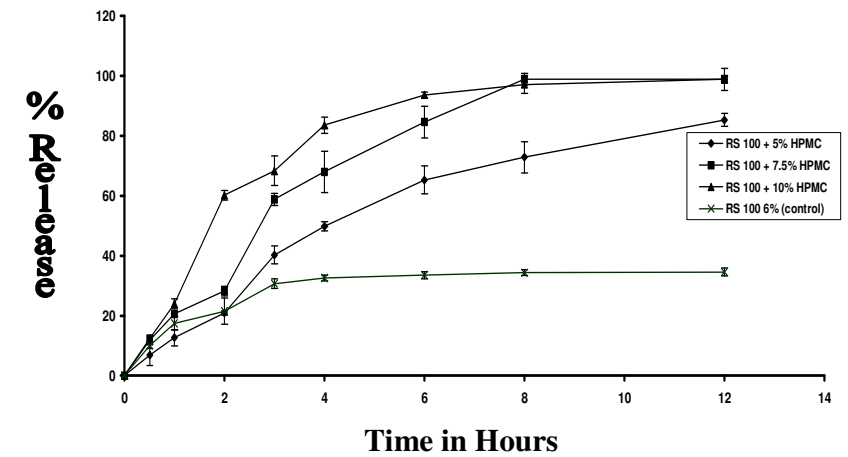

Fig 3 Release profiles of effervescent theophylline tablets on coating with $6 \%$ Eudragit RS 100 containing various concentrations of HPMC.

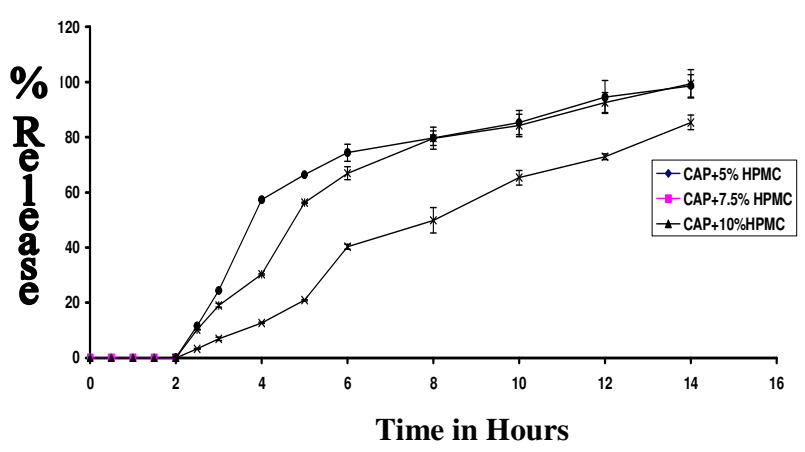

Fig 4: Release profiles of effervescent tablets primarily coated with RS 100 with different concentrations and finally over coated with CAP.

\section{CONCLUSIONS}

These results point out that 10\% HPMC contained in Eudragit RS 100 films, if coated with CAP as an over coat one, gives rise to optimal lag phase of 2 hours and thereafter a 'surge' release of theophylline. Such a delivery system may be worth evaluating for chronotherapeutic intervention of nocturnal asthma.

\section{REFERENCES}

Arkinstall WW. (1988) Review of the North American experience with evening administration of uniphyl tablets, in the treatment of nocturnal asthma, Am J Med. 85: 60-63.

Barnes PJ, Greeting AP, Neville L, Timmer J, Pole GW. (1982) Single dose slow release aminophylline at night prevents nocturnal asthma. Lancet. 1: 299-301.

Goldenheim PD, Conrad EA. (1987) Treatment of asthma by a controlled-release theophylline tablet formulation, Chronobol Int. 4: 397-408.

Fairfax AJ, McNabb WR, Davies HJ. (1980) Slow-release oral salbutamol and aminophylline in nocturnal asthma: relation of overnight changes in lung function and plasma drug levels. Thorax. 35:526-530.

Postma DS, Koeter GH, Keyzer JJ. (1986) Influence of slow-release terbutaline on the circadian variation of catecholamines. J Allergy Clin Immunol. 77: 471-77.

Martin RJ, Banks-Schelegel S. (1998) Chronobiology of asthama. Am J Respir Crit Care Med. 158:1002-1007.

Youan BBC. (2004) Chronopharmaceutics: gimmick or clinically relevant approach to drug delivery. Journal of Controlled release. 98: 337-353. 